\title{
CORRECTION
}

\section{Correction to: A non-linear analysis of running in the heavy and severe intensity domains}

\author{
Ben Hunter $^{1}$ (1) $\cdot$ Andrew Greenhalgh ${ }^{1} \cdot$ Bettina Karsten $^{2} \cdot$ Mark Burnley $^{3} \cdot$ Daniel Muniz-Pumares $^{1}$
}

Published online: 20 April 2021

(c) Crown 2021

\section{Correction to: European Journal of Applied Physiology https://doi.org/10.1007/s00421-021-04615-6}

The authors would like to correct the following errors in the publication of the article.

Unfortunately, Fig. 2 and Fig. 3 were published incorrectly in the original publication of the article and omitted superscript characters and presented incorrect values for the $\mathrm{x}$-axis. The complete, corrected Figs. 2 and 3 are given below.

The original article can be found online at https://doi.org/10.1007/ s00421-021-04615-6.

Ben Hunter

b.hunter3@herts.ac.uk

1 School of Life and Medical Sciences, University of Hertfordshire, Hatfield, UK

2 European University of Applied Sciences (EUFH), Berlin, Germany

3 Endurance Research Group, School of Sport and Exercise Sciences, University of Kent, Chatham Maritime, Chatham, UK 

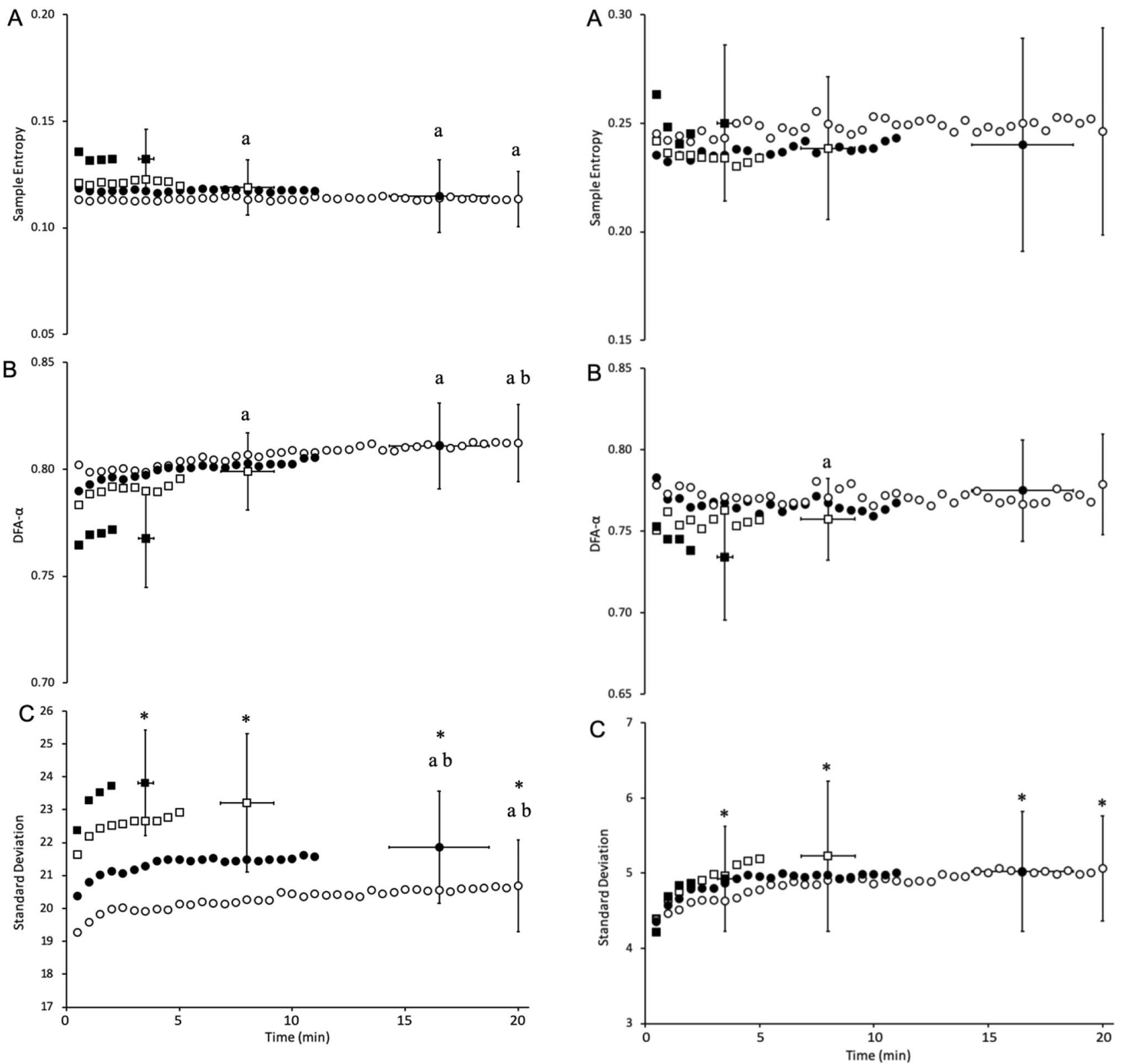

Fig. 2 Changes to hip flexion/extension sample entropy (a), DFA- $\alpha$ (b), and standard deviation (c) over the course of trials performed at 95\% CV (open circles), 100\% CV (black circles), 105\% CV (open squares), and $115 \% \mathrm{CV}$ (black squares). For clarity error bars $( \pm \mathrm{SD})$ have been omitted for all but the final data point. *Different from first

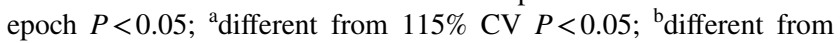
$105 \%$ CV $P<0.05$

Fig. 3 Changes to hip adduction/abduction sample entropy (a), DFA- $\alpha(\mathbf{b})$, and standard deviation (c) over the course of trials performed at $95 \% \mathrm{CV}$ (open circles), $100 \% \mathrm{CV}$ (black circles), $105 \% \mathrm{CV}$ (open squares), and $115 \% \mathrm{CV}$ (black squares). For clarity error bars $( \pm \mathrm{SD})$ have been omitted for all but the final data point. *Different

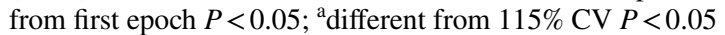

Publisher's Note Springer Nature remains neutral with regard to jurisdictional claims in published maps and institutional affiliations. 